\title{
AEROBIC AND ANAEROBIC PHYSICAL CAPACITIES PER STATION BASED ON FIELD TESTS OF ELITE MELANO-AFRICAN FOOTBALLERS IN HOT AND HUMID ENVIRONMENTS
}

\section{${ }^{* 1,2}$ Jean M. BAZABA KAYILOU, ${ }^{1}$ Eric A. MOUKOUYOU, ${ }^{2}$ Judith F. AHOUNOU AÏKPE, ${ }^{2}$ P. DANSOU and ${ }^{3}$ Joachim D. GBENOU}

1Biomécanique. Marien Ngouabi University. BP 69 Brazzaville, R. Congo

${ }^{2}$ Stress Physiology. University of Abomey Calavi. 01 BP 918 Cotonou, Benin

${ }^{3}$ Pharmacognosy and Essential Oils. Faculty of Health Sciences, Faculty of Science and Technology, University of Abomey Calavi. 01 BP 918 Cotonou, Benin

\section{ARTICLE INFO}

\section{Article History:}

Received $17^{\text {th }}$ August, 2019

Received in revised form

$03^{\text {rd }}$ September, 2019

Accepted $11^{\text {th }}$ October, 2019

Published online $30^{\text {th }}$ November, 2019

Key Words:

Parameters, Morphology,

Footballers, Environment.

*Corresponding author:

Jean M. BAZABA KAYILOU

\begin{abstract}
Anthropometric parameters and physical abilities are taken into account in the footballer's position on the field, for the achievement of good performance. The objective of this study was to assess the anthropometric parameters and physical capacities of Congolese elite footballers by position. Twenty-two (22) footballers aged $27.00 \pm 4.58$ years to $31.00 \pm 1.3$ years participated in the study. Anthropometric parameters (weight, height, calf and thigh circumference, lean mass and percentage fat mass) and physical capacities (maximum oxygen consumption, reaction rate and vertical expansion) were measured per shift during the championship. The results showed a significant difference $(\mathrm{p}<0.05)$, anthropometric parameters and physical capacities according to the position held. A positive correlation was observed between the two variables. In conclusion, Congolese footballers have a morphology and physique that differ by position in response to the practice of elite football. Football managers and coaches should place the training material at the footballer's development centre and integrate its evaluation into the annual activity planning.
\end{abstract}

Copyright (C) 2019, Bazaba KAYILOU et al. This is an open access article distributed under the Creative Commons Attribution License, which permits unrestricted use, distribution, and reproduction in any medium, provided the original work is properly cited.

Citation: Bazaba KAYILOU, JM., Eric A. MOUKOUYOU, Judith F. AHOUNOU AÏKPE, P. and DANSOU, Joachim D. GBENOU. 2019. “Aerobic and anaerobic physical capacities per station based on field tests of elite melano-african footballers in hot and humid environments", International Journal of Development Research, 09, (11), 31405-31409.

\section{INTRODUCTION}

Parameters, morphology, Footballers, Environment: Football performance is multifactorial (Bangsbo, 2008). It depends on technical, tactical, physical, physiological and psychological parameters (Stolen et al., 2005). To reach the highest level successfully, a well developed physical condition is necessary (Castagna et al., 2010). Optimizing the physical potential of footballers is one of the main objectives of football teams and training centers (Castagna et al., 2010). Previous studies have shown that the profiles of footballers differs according to the playing position (Bangsbo, 1994; Jovanovic et al., 2011).These authors indicate that goalkeepers are tall and heavy, midfielders are smaller and lighter (Castagna et al., 2010 ; Junior Bassett et al. 2000). In addition, there are also physiological differences in VO2max, with defenders and midfielders having the highest values (Bangsbo, 2008; Krustrup et al., 2006a).
The process of improving the physical capacities of Congolese elite footballers is characterized by loads adapted to the sports facilities and teaching materials available. Moreover, the failure of coaches to control the actual physical level of footballers is one of the reasons for this study. In view of the physical requirements of the footballers, in relation to environmental conditions, the determination of anthropometric parameters and physical capacities is essential to establish a standard profile of the Congolese footballer per playing position. This study aims to evaluate certain anthropometric parameters and physical capacities by playing position of elite footballers during the sports season.

\section{MATERIALS AND METHODS}

Subjects: A football team ranked in the top five of the Congolese national elite football championship was selected by the not probability, reasoned choice method. To participate 
in the study, footballers would have to meet the following criteria: have a valid sports license, have a 2 -year elite football license, reside in the Republic of Congo for the last two years, age between eighteen (18) and thirty (30), and give their free consent. Footballers with trauma were excluded from the sample. Thus, a total of twenty-two (22) footballers were selected to participate in this study.

Experimental approach: The study took place during the national elite football championship in Congo Brazzaville during the winter break. This study was carried out at the Laboratory of Exercise Physiology and Biomechanics (Marien Ngouabi University, Brazzaville) and the Laboratory of Exercise Physiology (University of Abomey Calavi, Benin). The study was approved by the scientific committee of the Marien Ngouabi University (Brazzaville), according to a standardized protocol (Lohman T.G et al., 1988). A pre-test was organized before the experiment to learn the tests and to familiarize the participants with the evaluation material. On the day of the tests, the participants had a quantified free breakfast 2 hours before the tests, and the tests took place in two days. Participants wore spiked shoes during the CMJ, yoyo, reaction speed, and the RSA tests. No other activities were carried out during the test days so that 24 hours of rest between each test day could be sufficient to ensure optimal recovery for the athletes. On the first day, the anthropometric parameters and physical capacities were measured; the second day concerned the physical capacities that were not measured on the first day.

Anthropometric measurements: The anthropometric parameters measured were height, obtained to within $0.1 \mathrm{~cm}$ using a Stanley. Body mass $(\mathrm{kg})$, body mass index $\left(\mathrm{kg} / \mathrm{m}^{2}\right)$, fat mass $(\%)$ and lean mass $(\mathrm{kg})$ were measured using a TANITA Corporation BC-545N impedance meter scale (JAPAN); measurements were taken without clothing and bare feet. The circumferences of the thigh and calf in $\mathrm{cm}$ were taken using a tape measure. For each anthropometric measurement, two consecutive measurements were taken to retain the mean value.

Physical performance tests: All tests were conducted in an atmosphere of $38^{\circ} \mathrm{c}$ and $50 \%$ humidity at the Brazzaville sports complex where the national championship matches are played on synthetic turf to simulate the playing conditions. Measurements included the counter-movement jump test with arms (CMJ), the reaction speed over $40 \mathrm{~m}$ and the Yo-yo R2. After a 15-minute warm-up with light runs, technical exercises, acceleration and stretching, the subjects performed the Counter Jump Movement (CMJ) tests and repeated 35 x 6 $\mathrm{m}$ sprints, respectively. These tests were interspersed with 10minute recovery periods to allow for recovery and to achieve the best performance during each test. The tests were conducted on a synthetic pitch reflecting the match conditions of the national football championship in Congo Brazzaville. For the vertical jump test (MJF), the subject starts from the $90^{\circ}$ bent position at the knee joints, to make a maximum upward push. He was allowed to do a prior flexion before the extension (plyometric test). This test was carried out in the field using a Myotest (UE). Three tests were performed for each footballer with $1 \mathrm{~min}$ recovery between tests and the best performance was chosen as the analysis value (Chamari et al., 2004; Ingebrigtsen et al., 2014). The fatigue index (IF) in percentage was obtained from repeated 35 × 6 m sprints using photoelectric cells (Microgate Corporation, UE). Players should run the 35-metre distance 6 times with 20 seconds of recovery between passes. The sprint time was measured by electric photocell barriers placed on the ground. Each sprint was initiated from a standing position with arms raised to chest height $20 \mathrm{~cm}$ behind the line of electric photocells (Mohr et al., 2010; Francesco Campa et al., 2018). Finally, the fatigue index (IF) was obtained using the equation described by Mohr et al. (2005).

\section{IF $(\%)=($ maximum power RAST-minimum power RAST $) /$ (maximum power RAST) X100}

Power $=(\text { weight } \mathrm{X} \text { distance })^{2} /$ time $^{2}$

On the second day of the tests, the subjects performed the same warm-up procedure before the tests. Then, they performed the reaction speed test over a distance of $40 \mathrm{~m}$ interspersed with $10 \mathrm{~m}$. The time was recorded using photoelectric cells (Microgate Corporation, EU). Subjects were allowed two passages after a 10-minute recovery period. The best performance was selected for analysis. After a 10-minute rest, the subjects performed the intermittent Yo-yo IR2 test (Bangsbo J, 1994) to determine the maximum oxygen consumption $\left(\mathrm{VO}_{2} \max \right)$. The test consists of running a distance of $20 \mathrm{~m}$ when indicated by the soundtrack. The subject rotates and returns to the starting point at the beep. He has an active recovery period of 10 seconds, during which the subject must walk or jog in the recovery area before returning to the starting point. A warning is given when the subject does not complete a successful return shuttle within the allotted time. Each player is placed under the responsibility of a secretary who is responsible for recording the number of rounds completed on a sheet of paper.

Statistical analysis: The variables were recorded and processed using the IBM SPSS Statistics 22 IBM Corporation (USA) software. Descriptive statistics were used to generate the means and standard deviations of the total sample. The normality of the data was verified by the Shapiro-Wilk test. A one-factor (game station) analysis of variance (ANOVA) was used to determine the differences in the performance of the player by the game station. When ANOVA was significant ( $p$ $<0.05)$, Tukey's HSD post hoc test was used to compare the different parameters. A Pearson correlation analysis was used to determine different relationships between the variables. The level of significance of the statistical tests was set at $p<0,05$.

\section{RESULTS}

The anthropometric characteristics are presented in (Table 1). No significant age differences were noted. Goalkeepers are taller $(\mathrm{p}=0.0044)$, heavier $(\mathrm{p}=0.048)$ than other players, a significant difference in thigh circumference was observed between goalkeepers and attackers $(\mathrm{p}=0.013)$. In addition, for fat mass $\%$, a significant difference was observed between defenders and attackers $(p=0.020)$. The average values of the vertical rebound of the player per playing position (Table 2) showed significant differences between goalkeeper and defenders $(\mathrm{p}=0.038)$ and between goalkeepers and midfielders $(p=0.005)$. However, a significant difference in leg strength was observed between defenders and midfielders $(p=0.038)$ and between midfielders and attackers $(p=0.035)$. The reaction speed from $10 \mathrm{~m}$ to $40 \mathrm{~m}$ (Table 3 ), showed a significant difference between defenders and attackers at $10 \mathrm{~m}$ 
Table 1. Anthropometric parameters of footballers by position held

\begin{tabular}{|c|c|c|c|c|c|}
\hline \multicolumn{6}{|c|}{ Playing station } \\
\hline & GB1 & GB2 & $\mathrm{DF}(\mathrm{n}=5)$ & $\mathrm{MT}(\mathrm{n}=7)$ & $\mathrm{AT}(\mathrm{n}=8)$ \\
\hline Age (year) & 27 & 26 & $27,8 \pm 1,8$ & $29,0 \pm 1,34$ & $27,5 \pm 3,3$ \\
\hline Weight (kg) & $75,3 *$ & 76,8 & $71,4 \pm 3,4$ & $65,9 \pm 2,5$ & $74,0 \pm 7,2$ \\
\hline Height (m) & $1,8^{*}$ & 1,78 & $1,7 \pm 0,6$ & $1,7 \pm 0,7$ & $1,7 \pm 0,7$ \\
\hline $\operatorname{IMC}\left(\mathrm{kg} \cdot \mathrm{m}^{-2}\right)$ & 23,3 & 24,23 & $23,3 \pm 1,4$ & $22,8 \pm 1,6$ & $23,3 \pm 1,1$ \\
\hline CirM (cm) & 34,0 & 35,32 & $36,1 \pm 2,1$ & $35,0 \pm 1,5$ & $37,2 \pm 2,0 *$ \\
\hline $\mathrm{CirC}(\mathrm{cm})$ & 52,0 & 51,68 & $55,3 \pm 2,6$ & $55,9 \pm 2,7$ & $56,6 \pm 2,6^{*}$ \\
\hline MM (kg) & 50,8 & 51,2 & $52,5 \pm 2,8$ & $52,5 \pm 3,30^{*}$ & $52,2 \pm 3,8$ \\
\hline $\mathrm{MG}(\%)$ & 11,1 & 11,5 & $11,1 \pm 1,4$ & $10,46 \pm 0,50$ & $9,9 \pm 0,6$ \\
\hline
\end{tabular}

BMI: Body mass index; *: Significant difference; GB: goalkeeper; DF: defender; MT: middle; AT: attacker, CirM: calf circumference; CirC: thigh circumference; MM: lean mass; MG: fat mass.

Table 2. Footballers' physical abilities by playing station

\begin{tabular}{llll}
\hline Playing station & CMJ $(\mathrm{cm})$ & PCMJ $(w)$ & LMB $(\mathrm{m})$ \\
\hline GB1 & 52,33 & 1076,31 & 15,30 \\
GB2 & $52,78^{*}$ & $1080,12^{*}$ & $15,45^{*}$ \\
DF $(\mathrm{n}=5)$ & $45,37 \pm 5,68$ & $1052,92 \pm 92,89$ & $12,59 \pm 0,13$ \\
MT $(\mathrm{n}=7)$ & $41,60 \pm 4,21$ & $915,35 \pm 51,41$ & $12,70 \pm 0,73$ \\
AT $(\mathrm{n}=8)$ & $43,10 \pm 4,06$ & $1049,24 \pm 133,44$ & $13,73 \pm 0,91$ \\
\hline
\end{tabular}

CMJ: against jump movement; PCMJ: Power against jump movement; LMB: Lancer medicine ball; GB: goalkeeper; DF: defender; MT; middle; AT: attacker, *: Significant difference.

Table 3. Footballers' reaction speed per game station

\begin{tabular}{llllll}
\hline Playing station & $\begin{array}{l}0-10 \mathrm{~m} \\
(\mathrm{~s})\end{array}$ & $\begin{array}{l}0-20 \mathrm{~m} \\
(\mathrm{~s})\end{array}$ & $\begin{array}{l}0-30 \mathrm{~m} \\
(\mathrm{~s})\end{array}$ & $\begin{array}{l}0-40 \mathrm{~m} \\
(\mathrm{~s})\end{array}$ & $\begin{array}{l}\mathrm{IF}_{\mathrm{SR}} \\
(\%)\end{array}$ \\
\hline GB1 & 1,98 & 3,24 & 4,31 & 5,63 & 32,00 \\
GB2 & 1,97 & 3,26 & 4,34 & 5,65 & 32,08 \\
DF $(\mathrm{n}=5)$ & $1,98 \pm 0,10$ & $2,99 \pm 0,15$ & $5,74 \pm 145,96$ & $5,33 \pm, 20$ & $46,05 \pm 2,15$ \\
ML $(\mathrm{n}=7)$ & $1,97 \pm 0,16$ & $3,15 \pm 0,14$ & $4,28 \pm 0,10$ & $5,39 \pm 0,11$ & $49,29 \pm 1,23$ \\
AT $(\mathrm{n}=8)$ & $1,56 \pm 0,56^{*}$ & $3,03 \pm 0,05^{*}$ & $4,08 \pm 0,17 *$ & $5,23 \pm 0,08^{*}$ & $50,49 \pm 2,04 *$ \\
\hline
\end{tabular}

0-10m: Speed 10m; 0-20m: Speed 20m; 0-30m: Speed 30m; 0-40m: Speed 40m; IFSR: Repeated sprint fatigue index; GB: goalkeeper; DF: defender; ML: midfield; AT: attacker, * : Significant difference.

Table 4. Physiological parameters of footballers by playing station in the yoyo test

\begin{tabular}{llllll}
\hline Playing station & $\begin{array}{l}\text { Fcr } \\
(\mathrm{bpm})\end{array}$ & $\begin{array}{l}\text { Fct } \\
(\mathrm{bpm})\end{array}$ & $\begin{array}{l}\text { Fcmax } \\
(\mathrm{bpm})\end{array}$ & $\begin{array}{l}\mathrm{V}_{\mathrm{O} 2 \mathrm{max}} \\
(\mathrm{mL} / \mathrm{kg} / \mathrm{min})\end{array}$ & $\begin{array}{l}\text { Fcmax } \\
(\%)\end{array}$ \\
\hline GB1 & 54 & 192 & 165 & 51,20 & 84 \\
GB2 & 54 & 192 & 166 & 51,58 & 83 \\
DF $(\mathrm{n}=5)$ & $59,00 \pm 7,55^{*}$ & $192,12 \pm 1,80$ & $171,75 \pm 3,75^{*}$ & $54,27 \pm 2,36^{*}$ & $89,39 \pm 2,18^{*}$ \\
ML $(\mathrm{n}=7)$ & $55,40 \pm 5,36$ & $189,00 \pm 2,34$ & $167,6 \pm 6,08$ & $53,99 \pm 1,85$ & $88,67 \pm 2,07$ \\
AT $(\mathrm{n}=8)$ & $56,20 \pm 3,88$ & $192,50 \pm 3,30$ & $169,28 \pm 4,53$ & $53,70 \pm 2,44$ & $88,36 \pm 2,06$ \\
\hline
\end{tabular}

Fcr: Rest heart rate; Fcmax: Maximum heart rate, Fct: Theoretical heart rate; VO2max: Maximum oxygen consumption; GB: goalkeeper; DF: defender; MT; middle; AT: attacker

Table 5. Correlation between anthropometric parameters and physical capacities

\begin{tabular}{lclllll}
\hline & Expansion technique & \multicolumn{4}{c}{ Reactivity Test } \\
\hline Parameters & CMJ & PCMJ & $0-10 \mathrm{~m}$ & $0-20 \mathrm{~m}$ & $0-30 \mathrm{~m}$ & $0-40 \mathrm{~m}$ \\
Weight & 0,140 & $0,845^{* * *}$ & 0,142 & $-0,125$ & $-0,103$ & $-0,255$ \\
Height & $0,475^{*}$ & $0,441^{*}$ & 0,006 & 0,028 & $-0,107$ & 0,175 \\
BMI & 0,071 & $0,460^{*}$ & 0,047 & 0,074 & 0,179 & $-0,066$ \\
CircM & 0,098 & $0,572^{* *}$ & 0,019 & $-0,076$ & $-0,045$ & $-0,201$ \\
\hline
\end{tabular}

BMI : Body mass index : CircM : Calf circumference ; CMJ : counter jump movement ; PCMJ : Power counter jump movement ; 0-10m : Speed 10m ; 0-20m : Speed 20m;0-30m : Speed 30m;0-40m : Speed 40m; *: Significant difference at $\mathrm{p}<0.05 ; * *$ : Significant difference at $\mathrm{p}<0.01 ; * * *$ : Significant difference at $\mathrm{p}<0.001$.

( $\mathrm{p}=0.024)$, between goalkeepers and defenders at $20 \mathrm{~m}(\mathrm{p}$ $=0.004)$, between goalkeepers and attackers $(\mathrm{p}=0.009)$, between defenders and midfielders $(p=0.017)$ and between midfielders and attackers $(p=0.049)$. With regard to running speed at $30 \mathrm{~m}$, significant differences were noted between goalkeepers and attackers $(p=0.049)$, between midfielders and attackers $(\mathrm{p}=0.040)$. At $40 \mathrm{~m}$, there was a difference between goalkeepers and defenders $(p=0.006)$ and midfielders and attackers $(p=0.037)$. With regard to the fatigue experienced during repeated sprints (Table 3 ), a significant difference was observed between field players and goalkeepers $(p=0.0001)$. On the other hand, a significant difference was observed between defenders and midfielders ( $p$ $=0.028)$ and between defenders and attackers $(p=0.01)$. The values of the maximum oxygen consumption of the player per playing station (Table 4) showed significant differences between the goalkeeper and the defenders $(p=0.046)$. The percentage of the average heart rate in the yoyo test determined their intensity according to the playing position. Defenders had the highest intensity in the yoyo test more than 
other players ( $89 \%$ Fcmax). The power of the upper limbs in the medical ball pitch showed a significant difference between goaltenders and strikers $(p=0.009)$ and between goaltenders and midfielders $(p=0.003)$. Finally, a relationship was noted between anthropometric parameters and the physical capacities of Congolese elite footballers (Table 5). The height of the jumps, which is closely related to the power of the legs, showed a correlation with the weight $(\mathrm{r}=0.845, \mathrm{P}<0.001)$ and calf circumference $(r=0.572, p<0.001)$ of the footballers playing in division 1 . The fatigue index for repeated sprints is a determining factor in the physical performance of the footballers which shows a correlation with the circumference of the thighs $(p=.0,436)$. The maximum oxygen consumption (Table 6) showed a correlation with the circumference of the thighs and calves of football players, respectively $(\mathrm{p}=0.544$, $\mathrm{p}=0.502$ ).

Table 6. Corrélation entre les paramètres anthropométriques et physiologiques

\begin{tabular}{lllll}
\hline \multicolumn{5}{l}{ Paramètres physiologiques } \\
\hline P.AT & Fcr & Fcmax & $\mathrm{VO}_{2} \max$ & IF_RSA \\
CircM & 0,083 & $-0,014$ & $0,502^{* *}$ & 0,336 \\
CircC & 0,049 & $-0,328$ & $0,544^{* *}$ & $0,436^{*}$ \\
\%MG & $-0,010$ & 0,123 & $0,778^{* * *}$ & $-0,225$ \\
\hline
\end{tabular}

P.AT: Anthropometric parameter; BMI: Body mass index; CircM: Calf circumference; CircC: Thigh circumference; MM: Lean mass; \%MG: Percentage fat mass; Fcr : Rest heart rate; Fcmax : Maximum heart rate ; VO2max : Maximum oxygen volume ; IF RSA : Repeated sprint fatigue index ; * : Significant difference at $\mathrm{p}<0.05 ;{ }^{* *}$ : Significant difference at $\mathrm{p}<$ $0.01, * * *$ : Significant difference at $\mathrm{p}<0.001$

\section{DISCUSSION}

The anthropometric parameters of Congolese footballers differ according to the playing position. Some footballers in relation to their playing position have had high body mass and fat percentage values. These parameters, at the goaltender level, were considerable as compared to other players, which contributed to the remarkable expression at the MJF. However, they were less efficient in the yoyo test and at $40 \mathrm{~m}$ reaction speed. This was expected, as it is well known that fat mass has a negative influence on football performance (Ingebrigtsen et al., 2014). Our results corroborate with the study by Gil et al. 2007. They assessed the morphological characteristics of the footballers by position. Several studies of elite footballers have shown that attackers have a higher muscle mass. (Mana Beatriz et al., 2017; Hencken White, 2006). The physical abilities showed a difference in values per playing position, the goaltenders presented different values to the MJF as compared to the other players. Our results are similar to the study by Loturco et al., 2017. The muscular power of the lower limbs is considered to be the determining factor of the performance (Capranica et al., 1992). The subjects of the study despite the lack of didactic material, power strength training developed their muscles because, most of the time, the coaches use muscle strengthening exercises of the lower limbs. In addition, the training sessions are conducted on sandy ground, the difficulty of the strides during the races brings an additional burden to the lower limbs.

In addition, other authors have assessed the anaerobic abilities of elite footballers on the relationship between speed, jump and strength abilities (Mana Beatriz et al., 2017). They showed that performance is linked to the abilities of sprints, strength and jumping. In this study, the reaction speed values were obtained per game station, the attackers have a more developed reaction speed than the other players. Our results are higher than those obtained by (Mana Beatriz et al., 2017), in semiprofessional footballers. In addition to the physical qualities of reaction speed, liveliness speed, velocity is the ability to sequence short and intense actions that characterize the highlevel player when he is well trained. Reference values in terms of jump, sprints and strength for footballers are scarce, although most of the available data are presented by the level of competition and position (Bloomfield et al., 2005; Hurley et al., 1984). The results of this study corroborate with those of the authors cited above. The reaction speed of the attackers over $40 \mathrm{~m}$ was more significant as compared to other players. Our results are close to those reported by Mana Beatriz et al., 2017, as well as with those obtained by other authors in the Tunisian and Senegalese junior players (Chamari et al., 2004; Cometti, 2002). The data obtained in this study will reinforce those in the literature for footballers working in difficult conditions; this is the strength of this study. In addition, there are other parameters involved in football performance, such as the $\mathrm{VO}_{2}$ max obtained indirectly by the intermittent yoyo test. It was more important for the defenders than for other players. In fact, it is suggested that this endurance test is one of the most instructive field tests for elite footballers (Carling et al., 2015; Fanchini et al., 2015). Maximum oxygen consumption $\left(\mathrm{VO}_{2} \mathrm{max}\right)$ is characterized by the total oxygen that an individual can use during high-intensity physical exercise (Fanchini et al., 2015). $\mathrm{V} 0_{2} \max$ is frequently used to measure the maximum cardiorespiratory level of individuals (Junior Bassett et al., 2000). A good aerobic capacity allows you to be more active and feel excessive fatigue during $2 \times 45 \mathrm{~min}$ of a game, to recover better between two or more intense efforts, and to increase your training capacity in duration and intensity (Fanchini et al., 2015). Our results are similar to the work reported by Stolen et al. (2005), who obtained V02max values between 50 and $75 \mathrm{ml} / \mathrm{kg} / \mathrm{min}$. Better oxygenation means better circulation and recovery capacity. This was supported by Francesco Campa1 et al. (2018) who demonstrated that the factors related to RSA performance were related to the level of aerobic capacity measured by the yo-yo test and the reaction speed over $20 \mathrm{~m}$. Similarly, the study by Stolen et al. (2005) showed that an improvement in $\mathrm{VO}_{2} \max$ with endurance training allows a good adaptation that leads to a decrease in the blood lactate levels.

\section{Conclusion}

The development of anthropometric parameters and physical capacities is essential for the achievement of a good performance in top-level football. The subjects of this study showed anthropometric and physical values that correspond to the practice of elite football. Differences in anthropometric parameters and physical abilities were observed per position played. In addition, optimal body composition, particularly low body fat and high calf muscle mass, can help improve physical performance and optimize the performance of the footballers.

\section{Practical Implementation}

Anthropometric parameters in football are decisive for the use of a player at a football match. The tallest and heaviest players are the defenders and attackers. The smallest and lightest players are the midfielders. Similarly, the development of physical qualities differs from one position to another. Field tests would be better suited for the evaluation of the footballer 
in his or her environment of expression. However, it is important for coaches to note that appropriate physical training at the position would promote the achievement of a good performance for the player and the team.

\section{Acknowledgements}

Conflict of Interest: The authors report that they have not received any funding related to the article and has no conflict of interest to declare.

\section{REFERENCES}

Bachero MB, Gonzalez SM, Jimenez RP, Badello JJ (2016). Evolution of determinant factors of repeated sprint ability. Shum Kinet 45: 115-26.

Bangsbo J, 2008. The physiology of soccer with special reference to intense intermittent exercise. Acta Physiol Scand Suppl 151: 1-155.

Bloomfield J, Polman R, Butterly R, O’Donoghue P. 2008. Analysis of age, stature, body mass, BMI and quality of elite soccer players from 4 European Leagues. J Sports Med Phys Fit 45: 58-67.

Capranica L, Cama G, Fanton F, Tessitore A, Figura F (1992). Force and power of preferred and non-preferred leg in young soccer players. J Sports Med Phys Fit 32: 358-63.

Carling C, Gregson W, McCall A, Moreira A, Wong P, Bradley PS. 2015. Match running performance during fixture congestion in elite soccer: research issues and future directions. Sports Med 45(5): 605-13. doi.org/10.1080/02640414.2016.1176228

Castagna C, Manzi V, Impellizzeri F, Weston M, Barbero Alvarez JC. 2010. Relationship between endurance field tests and match performance in young soccer players. $J$ Strength Cond Res 24: 3227-3233.

Chamari K, Hachana Y, Ahmed YB, Galy O, Sghaïer F, Chatard JC, Hue O, Wisløff U. 2004. Field and laboratory testing in young elite soccer players. $\mathrm{Br} \mathrm{J}$ Sports Med 38(2): 191-6. doi.org/ 10.1136/ bjsm.2002.004374

Cometti G. 2002. Physical Preparation in Football. In: Chiron. Paris. 34-36

Fanchini M, Schena F, Castagna C, Petruolo A, Combi F, McCall A et al. 2015. External responsiveness of the yoyo IR test level 1 in high-level male soccer players. Int $J$ Sports Med 36: 735-741.

Francesco Campa, Gabriele Semprini, Pedro B. Júdice, Gianluca Messina, Stefania Toselli 2018. Anthropometry, Physical and Movement Features, and Repeated-sprint Ability in Soccer Players. Int J Sports Med. https://doi.org/10.1055/a-0781-2473

Gil, S, Ruiz, F, Irazusta, A, Gil, J, Irazusta, J. 2007. Selection of young soccer players in terms of anthropometric and physiological factors. J Sports Med Phys Fitness 47: 2532 .
Hencken C, White C. Anthropometric assessment of Premiership soccer players in relation to playing position 2006. Eur J Sport Sci 6: 205-11.

Hurley B.F., Hagberg 1M., Allen W.K., Seals D.R., Young J.c., Cuddihee R.W., Holloszy 1O. 1984. Effect of training on blood lactate levels during submaximal exercise. $J$ Appl Physiol 56(5): 1260-4.

Ingebrigtsen J, Brochmann M, Castagna C, Bradley P, Ade , Krustrup P, Holtermann A. 2014. Relationships between field performance tests in high-level soccer players. $J$ Strength Cond Res 28: 942-949.

Jovanovic M, Sporis G, Omrcen D, Fiorentini F. 2011. Effects of speed, agility, quickness training method on power performance in elite soccer players. $J$ Strength Cond Res 25: $1285-92$.

Junior Bassett DR., Howley E.T. 2000. Factors for maximum oxygen uptake and determinants of endurance performance Med. Sei Sports Exere 32(1): 70-84.

Krustrup P, Mohr M, Nybo L, Jensen LM, Nielsen J.J, Bangsbo J (2006a). The Yo-Yo IR2 test: physiological response, reliability, and application to elite soccer. Med Sei Sports Exere 38(9): 1666-73.

Le Gall F, Carling C, Williams M, Reilly T. 2010. Anthropometric and fitness characteristics of international, professional and amateur male graduate soccer players from an elite youth academy. J Sci Med Sport13: 90-5.

Lohman T.G, ROCHE A.F, MARTORELL R. 1988. Anthropometry standardization reference manual. Champaign IL Hum Kinet.

Loturco I, Kobal R, Maldonado T, Piazzi AF, Bottino A, Kitamura K, Abad CCC, Pereira LA (2017). Jump squat is more related to sprinting and jumping abilities than olympic push press. Int J Sports Med 38: 604-612. DOI: 10.1055/s-0035-1565201

Mana Beatriz B, pareja Fernando, David Rodriguez-Roseil, Juan Manuel yanez-Garcia, Ricardo-Custodio, Juan José Gonzalez-Badillo 2017. Relationship between speed, jump and strength abilities and $800 \mathrm{~m}$ power in male athletes at the national and international level. J Hum Kinet 58-195.

Mohr M, Krustrup P, Bangsbo J. 2017. Fatigue in soccer: a brief review. J Sports Sci 23(6): 593-9. doi.org/10.1080/ 02640410400021286

Mohr M, Mujika I, Santisteban J. 2010. Examination of fatigue development in elite soccer in a hot environment: a multiexperimental approach. Scand J Med Sci Sports 20(Suppl. 3): 125-32.

Reilly T, Ekblom B. 2005. The use of recovery methods postexercise. J Sports Sci 23(6): 619-27.

Stolen T, Chamari K, Castagna C. and Wisloff V. 2005. Physiology of soccer: an update 35(6): 501-36. 